\title{
Outcomes of extracorporeal shock wave lithotripsy for ureteral stones according to ESWL intensity
}

\author{
Ji Hyung Yoon, Sejun Park, Seong Cheol Kim, Sungchan Park, Kyung Hyun Moon, Sang Hyeon Cheon, \\ Taekmin Kwon^
}

Department of Urology, Ulsan University Hospital, University of Ulsan College of Medicine, Ulsan, Korea

Contributions: (I) Conception and design: JH Yoon, T Kwon; (II) Administrative support: JH Yoon, T Kwon; (III) Provision of study materials or patients: All authors; (IV) Collection and assembly of data: All authors; (V) Data analysis and interpretation: All authors; (VI) Manuscript writing: All authors; (VII) Final approval of manuscript: All authors.

Correspondence to: Taekmin Kwon, MD, PhD. Department of Urology, Ulsan University Hospital, University of Ulsan College of Medicine, 877 Bangeojinsunwando-ro, Dong-gu, Ulsan, 44033, Korea. Email: tmkwon@uuh.ulsan.kr.

Background: We evaluated the treatment outcomes of ureteral stones according to energy intensity generated by extracorporeal shock wave lithotripsy (ESWL).

Methods: We retrospectively analyzed 150 patients who underwent ESWL for treatment of ureteral stones between September 2018 and February 2020. All stones were confirmed by a computed tomography examination, and the size, location, skin-to-stone distance, and Hounsfield units (HU) of the stones were assessed. In addition, patient characteristics including body mass index and estimated glomerular filtration rate, which can affect treatment outcome, were also evaluated. The success or failure of ESWL was confirmed according to the session, and the factors affecting the treatment outcome were analyzed using a logistic regression model.

Results: Of the 150 patients, $82(54.7 \%)$ had stones in the proximal ureter, $5(3.3 \%)$ in the mid, and $63(42.0 \%)$ in the distal ureter. Patients underwent ESWL an average of 1.5 times, and the success rate according to session was $65.3 \%$ for the first, $83.3 \%$ for the second, and $90.0 \%$ for the third session. A multivariate analysis revealed that stone size [odds ratio (OR) $0.81,95 \%$ confidence interval (CI), 0.66-0.99, $\mathrm{P}=0.049$ ] and $\mathrm{HU}(\mathrm{OR} 0.99,95 \% \mathrm{CI}, 0.98-0.99, \mathrm{P}=0.001)$ were significant factors affecting the success rate after the first ESWL session; ESWL intensity was not related to success rate. Stone size (OR 0.78, 95\% CI, $0.62-0.96, \mathrm{P}=0.022$ ) was the only significant factor affecting the success rate in the third session.

Conclusions: Stone size and HU affected the ESWL success rate. ESWL intensity was not significantly related to the success rate, so it should be adjusted according to patient pain and the degree of stone fragmentation.

Keywords: Ureteral calculus; lithotripsy; extracorporeal shockwave therapy; treatment outcome

Submitted Nov 06, 2020. Accepted for publication Jan 19, 2021.

doi: $10.21037 /$ tau-20-1397

View this article at: http://dx.doi.org/10.21037/tau-20-1397

$\wedge$ ORCID: 0000-0003-2280-319X. 


\section{Introduction}

Extracorporeal shock wave lithotripsy (ESWL) has been used widely due to its relatively high efficacy and noninvasive nature for treating urinary stones (1). ESWL has a satisfactory treatment effect, particularly for ureteral stones $<1 \mathrm{~cm}$. ESWL can replace invasive treatment using a ureteroscope, and the European Association of Urology (EAU) guidelines suggest ESWL as the first treatment option for stones $<1 \mathrm{~cm}(2,3)$.

The success rate of ESWL depends on various factors, such as stone (location, density, size, and components), renal anatomy (hydronephrosis, calyceal diverticulum, ureteral obstruction and stenosis, and urinary anomaly), and patientrelated factors (skin-to-stone distance, obesity, and renal function) (4). Also, various methods to improve the success rate of ESWL have been studied. A shock wave frequency of 60-90 shock waves/min improves the stone-free rate (SFR), and tissue damage decreases with a low shock wave frequency $(5,6)$. Recent studies recommend increasing the power step-by-step, as this ramping technique improves stone fragmentation and reduces renal injury during ESWL (7-11). Additionally, medical expulsive therapy (MET) is efficient for relieving pain and the passage of a stone (12); however, the types of shock waves generated by other methods are not successful (9).

However, no study has investigated the final energy intensity of ESWL. A higher final energy intensity may generally induces a better SFR in clinical practice. Although a higher final energy intensity may lead to better performance, it can cause other side effects, such as pain and injury to the urinary tract. If there was no difference in the SFR according to intensity, we would be able to safely perform ESWL without increasing the energy intensity. Therefore, we performed this study to evaluate the treatment outcomes of ureteral stones according to ESWL energy intensity. We present the following article in accordance with the STROBE reporting checklist (available at http://dx.doi.org/10.21037/tau-20-1397).

\section{Methods}

\section{Study participants}

We retrospectively analyzed patients who had undergone ESWL for ureteric stones at our hospital from September 2018 to February 2020. During the study period, a total of 172 patients underwent ESWL for the first time, of which 150 patients excluding renal stones were included in the study. The ESWL procedure was delayed if the patient had a urinary tract infection.

We used the Dornier Compact Delta/Sigma model as the ESWL device, and this electromagnetic model can confirm intensity (a-c and 1-3, Table 1). ESWL was practiced as a ramping technique, but if patients complained of pain, we stopped increasing the intensity. We used the last continuous intensity for analyses. About 3,000 shocks were delivered at a frequency of $70-80 / \mathrm{min}$. No analgesia was provided during the procedure. Patients who had proximal ureter stones were treated in the supine position, otherwise mid and distal ureter stones were treated in the prone position to avoid bony structures. Targeting was performed mostly by fluoroscopy.

\section{Outcome measures}

All patients underwent a baseline evaluation of the kidneys, ureter, and bladder (KUB) and an abdominopelvic computed tomography (CT) (non-enhanced or enhanced) scan. The maximum diameter of the stone, location of the stone, skin-to-stone distance (SSD), and average Hounsfield units (HU) were evaluated. The SSD was calculated on the CT scan using three measured distances from the center of the stone to the skin $\left(0^{\circ}, 45^{\circ}\right.$, and $\left.90^{\circ}\right)$. The average SSD was obtained from these values and marked as the representative SSD for each stone. Average HUs were

Table 1 Shock wave parameters-intensity setting

\begin{tabular}{|c|c|c|c|c|c|c|}
\hline Intensity levels & a & $\mathrm{b}$ & c & 1 & 2 & 3 \\
\hline Disintegrating energy $E(12 \mathrm{~mm})$ & 2.5 & 3.7 & 7.0 & 11.0 & 20.0 & 29.0 \\
\hline Energy flux density ED $\left(\mathrm{mJ} / \mathrm{mm}^{2}\right)$ & 0.03 & 0.07 & 0.11 & 0.15 & 0.28 & 0.44 \\
\hline Max. pulse repetition frequency (RPF) shot/min & 180 & 180 & 180 & 120 & 120 & 120 \\
\hline
\end{tabular}


Table 2 Per procedure and outcome data

\begin{tabular}{|c|c|}
\hline Variable & Value \\
\hline No. patients & 150 \\
\hline Age (years) & $52.1 \pm 14.2[19-87]$ \\
\hline \multicolumn{2}{|l|}{ Sex } \\
\hline Male & $104(69.3)$ \\
\hline Female & $46(30.7)$ \\
\hline BMl $\left(\mathrm{kg} / \mathrm{m}^{2}\right)$ & $23.3 \pm 4.5(17.7-36.2)$ \\
\hline Stone size $(\mathrm{mm})$ & $7.2 \pm 3.4(3.0-37.0)$ \\
\hline $\mathrm{SSD}(\mathrm{mm})$ & $95.6 \pm 15.2(65.3-134.7)$ \\
\hline $\mathrm{HU}$ & $673.6 \pm 267.9(184-1,416)$ \\
\hline \multicolumn{2}{|l|}{ Side } \\
\hline Right & $73(48.7)$ \\
\hline Left & 77 (51.3) \\
\hline \multicolumn{2}{|l|}{ Location } \\
\hline Proximal & $82(54.7)$ \\
\hline Mid & $5(3.3)$ \\
\hline Distal & $63(42.0)$ \\
\hline Preoperative $\mathrm{Cr}$ & $0.93 \pm 0.23(0.56-1.6)$ \\
\hline Preoperative eGFR & $92.5 \pm 51.2(45.3-129.5)$ \\
\hline Total No. ESWL & $1.5 \pm 0.9[1-8]$ \\
\hline \multicolumn{2}{|l|}{ ESWL intensity } \\
\hline$a-c$ & $6(4.0)$ \\
\hline 1 & $36(24.0)$ \\
\hline 2 & $85(56.7)$ \\
\hline 3 & $23(15.3)$ \\
\hline \multicolumn{2}{|l|}{ Pain during ESWL } \\
\hline None & $77(51.3)$ \\
\hline Mild & $69(46.0)$ \\
\hline Severe & $4(2.7)$ \\
\hline \multicolumn{2}{|l|}{ SFR after each session } \\
\hline $1 \mathrm{st}$ & 98 (65.3) \\
\hline 2nd & $125(83.3)$ \\
\hline $3 r d$ & $135(90.0)$ \\
\hline \multicolumn{2}{|c|}{ Complications (Clavien-Dindo) } \\
\hline Grade 1 & $3(2.0)$ \\
\hline Voiding difficulty & 1 \\
\hline Hematuria & 2 \\
\hline Alpha blocker & $120(80.0)$ \\
\hline
\end{tabular}

Values are presented as mean \pm SD (range) and/or frequency (\%) appropriate. BMI, body mass index; SSD, skin-to-stone distance; HU, Hounsfield units; ESWL, extracorporeal shock wave lithotripsy. calculated on the CT scan using the mean attenuation of three consistent areas $\left(0.02 \mathrm{~cm}^{2}\right)(13)$. In addition, patient characteristics, including age, sex, body mass index (BMI), and estimated glomerular filtration rate (eGFR), which can affect treatment outcomes, were also assessed. Pain was recorded as no pain, mild, or severe. We also investigated the use of alpha blockers. Most patients were followed up 7 days after ESWL, for a check of the KUB or for a CT scan. If a stone was $<4 \mathrm{~mm}$ or disappeared, we regarded it as a success. All radiological factors were read by a radiologist in the genitourinary division of the radiology department of our institution. This reader was unaware of the clinical findings and analyzed the images independently. If ESWL repeatedly failed or the patient had severe pain due to stones, we considered surgery.

\section{Statistical analysis}

The data were examined to identify clinical and radiological factors that were correlated with treatment outcome. The success or failure of ESWL was confirmed according to the session, and the factors affecting treatment outcomes were analyzed using a logistic regression model. A univariate analysis was used to individually assess the association between the various factors and treatment outcomes. Thereafter, variables that were significant $(\mathrm{P}<0.2)$ in the univariate analysis were included in a multivariate logistic regression analysis to identify the independent predictors of treatment outcomes. All statistical tests were two-sided, and a $\mathrm{P}$ value $<0.05$ was considered significant. Data were analyzed using IBM SPSS Statistics Version 24 software (IBM Corp., Somers, NY, USA). We also examined the characteristics of the stones that had been removed endoscopically under general anesthesia due to failed ESWL.

\section{Ethics statement}

This study was conducted in accordance with the Declaration of Helsinki (as revised in 2013). This study was approved by our institutional review board (IRB No. UUH2020-06-002) and individual consent for this retrospective analysis was waived.

\section{Results}

The characteristics of the patients before and after the procedure are presented in Table 2. The mean age of the 
Table 3 Logistic regression analysis for different factors affecting the success rate after the first ESWL session

\begin{tabular}{|c|c|c|c|c|}
\hline Variable & \multicolumn{2}{|c|}{ Univariate } & \multicolumn{2}{|c|}{ Multivariable $^{\star}$} \\
\hline Age (continuous) & $0.99(0.97-1.02)$ & 0.563 & - & - \\
\hline Sex (female) & $0.99(0.48-2.06)$ & 0.984 & - & - \\
\hline Body mass index (continuous) & $0.99(0.87-1.12)$ & 0.878 & - & - \\
\hline SSD (continuous) & $1.01(0.98-1.03)$ & 0.519 & - & - \\
\hline HU (continuous) & $0.95(0.98-0.99)$ & 0.001 & $0.99(0.98-0.99)$ & 0.001 \\
\hline \multicolumn{5}{|l|}{ Ureteral stone location } \\
\hline Proximal & Ref & & & \\
\hline Preoperative eGFR (continuous) & $0.99(0.97-1.01)$ & 0.988 & & \\
\hline \multicolumn{5}{|l|}{ ESWL intensity } \\
\hline$a-c$ & Ref & & & \\
\hline 1 & $1.50(0.23-9.61)$ & 0.669 & & \\
\hline 2 & $0.79(0.14-4.54)$ & 0.790 & & \\
\hline 3 & $0.94(1.40-6.28)$ & 0.947 & & \\
\hline
\end{tabular}

*, significant variables $(\mathrm{P}<0.2)$ according to the univariate analysis were included in the multivariable analysis. SSD, skin-to-stone distance; HU, Hounsfield units; ESWL, extracorporeal shock wave lithotripsy.

patients was 52.1 years, and $104(69.3 \%)$ of 150 were male. The mean stone size was $7.2 \mathrm{~mm}$, SSD was $95.6 \mathrm{~mm}$, and HU was 673.6 . Of the 150 patients, $82(54.7 \%)$ had stones in the proximal ureter, $5(3.3 \%)$ in the mid, and $63(42.0 \%)$ in the distal ureter. The average pre-procedural serum creatinine was $0.93 \mathrm{mg} / \mathrm{dL}$, and eGFR was $92.5 \mathrm{~mL} / \mathrm{min} / 1.73 \mathrm{~m}^{2}$. Patients underwent ESWL an average of 1.5 times, and the success rate according to the session was $65.3 \%$ for the first, $83.3 \%$ for the second, and $90.0 \%$ for the third session. Complications occurred in three patients, but all were mild grade 1 symptoms. An alpha blocker was used for MET by 120 patients $(80 \%)$.

A univariate analysis using a logistic regression model showed that stone size and HU were significant predictors of success after the first ESWL session. The multivariate analysis revealed that stone size [odds ratio (OR) 0.81, 95\% CI, 0.66-0.99, P=0.049] and HU (OR 0.99, 95\% CI, 0.98$0.99, \mathrm{P}=0.001)$ were significant factors affecting success; ESWL intensity was not related to the success rate (Table 3).

Stone size and HU were significant predictors of success of the third session in the univariate analysis, but stone size (OR 0.78, 95\% CI, 0.62-0.96, $\mathrm{P}=0.022$ ) was the only significant factor affecting the success rate in the multivariate analysis (Table 4).

Fifteen patients underwent endoscopic removal due to failed ESWL, and they had larger stones (10.5 vs. $6.8 \mathrm{~mm}$, $\mathrm{P}=0.001$ ) with higher HU (919.7 vs. 651.9, $\mathrm{P}=0.001)$ (Table 5).

\section{Discussion}

Clinicians generally believe that high intensity ESWL can induce a high SFR, but intensity did not affect the SFR in this study. A repeat procedure increased the SFR about $90 \%$ in this study. Although ESWL is a very safe procedure, it rarely causes life-threatening complications, such as renal hematoma or surrounding organ injuries. Therefore, it is not recommended to try every stone treatment completely during only one procedure with high and risky energy levels. What is more important than intensity is using the energy ramping technique. A fixed ESWL intensity has an 
Table 4 Logistic regression analysis for different factors affecting the success rate after the third ESWL session

\begin{tabular}{|c|c|c|c|c|}
\hline Variable & \multicolumn{2}{|c|}{ Univariate } & \multicolumn{2}{|c|}{ Multivariable $^{\star}$} \\
\hline Age (continuous) & $1.01(0.97-1.04)$ & 0.815 & - & - \\
\hline Sex (female) & $1.24(0.37-4.13)$ & 0.724 & - & - \\
\hline Body mass index (continuous) & $1.12(0.93-1.35)$ & 0.241 & - & - \\
\hline SSD (continuous) & $1.03(0.99-1.07)$ & 0.158 & $1.02(0.97-1.07)$ & 0.402 \\
\hline HU (continuous) & $0.99(0.98-0.99)$ & 0.001 & $0.99(0.99-1.00)$ & 0.106 \\
\hline \multicolumn{5}{|l|}{ Ureteral stone location } \\
\hline Proximal & Ref & & & \\
\hline Preoperative eGFR (continuous) & $1.01(0.98-1.03)$ & 0.607 & & \\
\hline \multicolumn{5}{|l|}{ ESWL intensity } \\
\hline$a-c$ & Ref & & & \\
\hline 1 & $1.60(0.15-17.38)$ & 0.699 & & \\
\hline 2 & $1.69(0.18-16.11)$ & 0.649 & & \\
\hline 3 & $4.40(0.23-82.97)$ & 0.323 & & \\
\hline
\end{tabular}

*, significant variables $(\mathrm{P}<0.2)$ according to the univariate analysis were included in the multivariable analysis. SSD, skin-to-stone distance; $\mathrm{HU}$, Hounsfield units; ESWL, extracorporeal shock wave lithotripsy.

Table 5 Stone characteristics according to surgical condition

\begin{tabular}{lccc}
\hline Variable & URS & No URS & P value \\
\hline No. patients & 15 & 135 & - \\
Stone size $(\mathrm{mm})$ & $10.5 \pm 8.2$ & $6.8 \pm 2.2$ & 0.001 \\
SSD $(\mathrm{mm})$ & $88.5 \pm 21.3$ & $96.2 \pm 14.5$ & 0.124 \\
HU & $919.7 \pm 282.8$ & $651.9 \pm 256.6$ & 0.001 \\
Location & & & 0.381 \\
Proximal & $10(66.7)$ & $72(53.3)$ & \\
$\quad$ Mid & $1(6.7)$ & $4(3.0)$ & \\
$\quad$ Distal & $4(26.6)$ & $59(43.7)$ & \\
\hline
\end{tabular}

Values are presented as mean \pm SD and/or frequency (\%) appropriate. URS, ureteroscopy; SSD, skin-to-stone distance; HU, Hounsfield units; ESWL, extracorporeal shock wave lithotripsy. obvious disadvantage, called the screening effect, whereby the powder generated and fine fragments by the cavitation bubbles and stress waves cluster around the residual stones to attenuate and scatter the shock waves (14-16). Thus, the "ramping technique" of gradually escalating intensity was introduced. It was hypothesized that this technique strengthens the formation of cavitation bubbles and recompenses for the screening effect $(11,14)$. This method prepares the patient to adapt to the sense of SWL. Then, according to the EAU guidelines, the ramping technique produces less renal damage, with level $1 \mathrm{~b}$ evidence (3). A randomized study using a stepwise voltage ramping protocol versus a fixed power group in 418 patients reported that the ramping technique causes fewer renal hematomas (5.6\%), compared with fixed power (13\%) (17). The reason for this 
safety is that the initial low shockwave energy constricts the renal vessels, making the kidney less susceptible to damage during the following application of a higher energy intensity $(18,19)$.

Stone size was inversely proportional to the ESWL result. Many studies have reported that stone size is a significant factor related to SFR after ESWL (20-22). In particular, ESWL more frequently fails for stones $>10 \mathrm{~mm}$. The results of treating stones $<10 \mathrm{~mm}$ are superior in all locations of the ureter to those of stones $>10 \mathrm{~mm}(3,21)$. In our study, stone size was a significant factor not only in the first session, but also in the third session with a high success rate of $90 \%$ in the multivariate analysis for predicting the success rate.

The density of calculi on an axial CT image has also been studied as a predictor of the fragmentation and treatment outcome (10). The relationship between stone density and the degree of fragmentation was first reported in vitro. As the density of a stone increases, more shockwaves are needed to break the stone (23). Similarly, in several clinical studies, more than three ESWL sessions were required in patients with stone densities $>750 \mathrm{HU}$ compared to those with stone densities $\leq 750 \mathrm{HU}$ (24). In addition, several researchers have reported that ESWL is more likely to fail in patients with a stone density $>750-1,000 \mathrm{HU}$, and these patients should consider other treatment modalities $(25,26)$. In our series, the HU of the stone was also a significant predictor for the first ESWL session. Several ESWL session were unsuccessful in cases of stones with a high $\mathrm{HU}$, and endoscopic removal was often performed. Thus, we should be prepared for ESWL failure if a stone is $>10 \mathrm{~mm}$ and 1,000 HU.

According to several studies, SSD is an important predictor of treatment outcome for ureteral stones $(27,28)$. If the distance to the stone increases, the energy transfer decreases due to fat distribution. A cutoff SSD $>10-12 \mathrm{~cm}$ predicts ESWL failure in most cases. In our series, SSD was not a significant factor for predicting ESWL success.

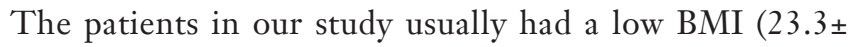
$\left.4.5 \mathrm{~kg} / \mathrm{m}^{2}\right)$, so it was difficult to generate a difference due to the short SSD $(95.6 \pm 15.2)$. In addition, it may be difficult to determine the difference because a proximal stone, which is difficult to pass, has a shorter SSD than a distal stone. More research will confirm the importance of SSD in the treatment of ureteral calculi, regardless of the stone location.

Although the investigators did not know the value when determining ESWL or analyzing the results, this study included potential weaknesses because of its retrospective nature. Another limitation is that CT cannot be used to evaluate success after the procedures. CT detects urinary calculi with very high accuracy and it seems to be the method of choice for detecting residual stones. Confirmation of ESWL results through a KUB X-ray increases the success rate. In contrast, considering the limitations of plain films, the occurrence of residual stones may be higher due to bowel gas, feces, and soft tissue overlap. This current study, like most ESWL research, has the same problem. It is not known whether these results translate to different types and brands of ESWL. This is the first study to analyze success rates according to ESWL intensity. That is, this study is an important basis for safe ESWL without unnecessary increases in ESWL intensity. Further studies with more patients and a higher ESWL intensity will confirm these results.

\section{Conclusions}

Stone size and HU affected the ESWL success rate, and several ESWL sessions or endoscopic removal was often required when stones were large with high HU. ESWL intensity was not significantly related to the success rate, so intensity should be adjusted according to patient pain and the degree of stone fragmentation.

\section{Acknowledgments}

Funding: None.

\section{Footnote}

Reporting Checklist: The authors have completed the STROBE reporting checklist. Available at http://dx.doi. org/10.21037/tau-20-1397

Data Sharing Statement: Available at http://dx.doi. org/10.21037/tau-20-1397

Peer Review File: Available at http://dx.doi.org/10.21037/tau20-1397

Conflicts of Interest: All authors have completed the ICMJE uniform disclosure form (available at http://dx.doi. org/10.21037/tau-20-1397). The authors have no conflicts 
of interest to declare.

Ethical Statement: The authors are accountable for all aspects of the work in ensuring that questions related to the accuracy or integrity of any part of the work are appropriately investigated and resolved. This study was conducted in accordance with the Declaration of Helsinki (as revised in 2013). This study was approved by our institutional review board (IRB No. UUH-2020-06-002) and individual consent for this retrospective analysis was waived.

Open Access Statement: This is an Open Access article distributed in accordance with the Creative Commons Attribution-NonCommercial-NoDerivs 4.0 International License (CC BY-NC-ND 4.0), which permits the noncommercial replication and distribution of the article with the strict proviso that no changes or edits are made and the original work is properly cited (including links to both the formal publication through the relevant DOI and the license). See: https://creativecommons.org/licenses/by-nc-nd/4.0/.

\section{References}

1. Skolarikos A, Alivizatos G, de la Rosette J. Extracorporeal shock wave lithotripsy 25 years later: complications and their prevention. Eur Urol 2006;50:981-990; discussion 990.

2. Torricelli FC, Danilovic A, Vicentini FC, et al. Extracorporeal shock wave lithotripsy in the treatment of renal and ureteral stones. Rev Assoc Med Bras (1992) 2015;61:65-71.

3. Türk C, Petř́k A, Sarica K, et al. EAU Guidelines on Interventional Treatment for Urolithiasis. Eur Urol 2016;69:475-82.

4. Assimos DG. Re: EAU Guidelines on Interventional Treatment for Urolithiasis. J Urol 2016;195:659.

5. Paterson RF, Lifshitz DA, Lingeman JE, et al. Stone fragmentation during shock wave lithotripsy is improved by slowing the shock wave rate: studies with a new animal model. J Urol 2002;168:2211-5.

6. Greenstein A, Matzkin H. Does the rate of extracorporeal shock wave delivery affect stone fragmentation? Urology 1999;54:430-2.

7. Al-Dessoukey AA, Abdallah M, Moussa AS, et al. Ultraslow full-power shock wave lithotripsy versus slow power-ramping shock wave lithotripsy in stones with high attenuation value: A randomized comparative study. Int J
Urol 2020;27:165-70.

8. He Z, Deng T, Yin S, et al. Energy output modalities of shockwave lithotripsy in the treatment of urinary stones: escalating or fixed voltage? A systematic review and metaanalysis. World J Urol 2020;38:2443-53.

9. Lee SM, Collin N, Wiseman H, et al. Optimisation of shock wave lithotripsy: a systematic review of technical aspects to improve outcomes. Transl Androl Urol 2019;8:S389-S397.

10. Ahmed AF, Gabr AH, Emara AA, et al. Factors predicting the spontaneous passage of a ureteric calculus of $10 \mathrm{~mm}$. Arab J Urol 2015;13:84-90.

11. Rabah DM, Mabrouki MS, Farhat KH, et al. Comparison of escalating, constant, and reduction energy output in ESWL for renal stones: multi-arm prospective randomized study. Urolithiasis 2017;45:311-6.

12. Skolarikos A, Grivas N, Kallidonis P, et al. The Efficacy of Medical Expulsive Therapy (MET) in Improving Stonefree Rate and Stone Expulsion Time, After Extracorporeal Shock Wave Lithotripsy (SWL) for Upper Urinary Stones: A Systematic Review and Meta-analysis. Urology 2015;86:1057-64.

13. Tanaka M, Yokota E, Toyonaga Y, et al. Stone attenuation value and cross-sectional area on computed tomography predict the success of shock wave lithotripsy. Korean J Urol 2013;54:454-9.

14. Zhou Y, Cocks FH, Preminger GM, et al. The effect of treatment strategy on stone comminution efficiency in shock wave lithotripsy. J Urol 2004;172:349-54.

15. Maloney ME, Marguet CG, Zhou Y, et al. Progressive increase of lithotripter output produces better in-vivo stone comminution. J Endourol 2006;20:603-6.

16. El-Mowafi H, El-Sherbiny M, Abou-ElGhar M, et al. Acetabular coverage in bladder exstrophy: role of 3-dimensional computed tomography. Acta Orthop Belg 2005;71:410-3.

17. Skuginna V, Nguyen DP, Seiler R, et al. Does Stepwise Voltage Ramping Protect the Kidney from Injury During Extracorporeal Shockwave Lithotripsy? Results of a Prospective Randomized Trial. Eur Urol 2016;69:267-73.

18. Willis LR, Evan AP, Connors BA, et al. Prevention of lithotripsy-induced renal injury by pretreating kidneys with low-energy shock waves. J Am Soc Nephrol 2006;17:663-73.

19. Handa RK, Bailey MR, Paun M, et al. Pretreatment with low-energy shock waves induces renal vasoconstriction during standard shock wave lithotripsy (SWL): a treatment protocol known to reduce SWL-induced renal injury. BJU 
Int 2009;103:1270-4.

20. Argyropoulos AN, Tolley DA. Failure after shockwave lithotripsy: is outcome machine dependent? Int J Clin Pract 2009;63:1489-93.

21. Hatiboglu G, Popeneciu V, Kurosch M, et al. Prognostic variables for shockwave lithotripsy (SWL) treatment success: no impact of body mass index (BMI) using a third generation lithotripter. BJU Int 2011;108:1192-7.

22. Choi JW, Song PH, Kim HT. Predictive factors of the outcome of extracorporeal shockwave lithotripsy for ureteral stones. Korean J Urol 2012;53:424-30.

23. Saw KC, McAteer JA, Fineberg NS, et al. Calcium stone fragility is predicted by helical CT attenuation values. J Endourol 2000;14:471-4.

24. Gupta NP, Ansari MS, Kesarvani P, et al. Role of computed tomography with no contrast medium enhancement in predicting the outcome of extracorporeal shock wave lithotripsy for urinary calculi. BJU Int 2005;95:1285-8.

Cite this article as: Yoon JH, Park S, Kim SC, Park S, Moon KH, Cheon SH, Kwon T. Outcomes of extracorporeal shock wave lithotripsy for ureteral stones according to ESWL intensity. Transl Androl Urol 2021;10(4):1588-1595. doi: 10.21037/tau-201397
25. Pareek G, Armenakas NA, Fracchia JA. Hounsfield units on computerized tomography predict stone-free rates after extracorporeal shock wave lithotripsy. J Urol 2003;169:1679-81.

26. Pareek G, Armenakas NA, Panagopoulos G, et al. Extracorporeal shock wave lithotripsy success based on body mass index and Hounsfield units. Urology 2005;65:33-6.

27. Wiesenthal JD, Ghiculete D, D'A Honey RJ, et al. Evaluating the importance of mean stone density and skin-to-stone distance in predicting successful shock wave lithotripsy of renal and ureteric calculi. Urol Res 2010;38:307-13.

28. Perks AE, Schuler TD, Lee J, et al. Stone attenuation and skin-to-stone distance on computed tomography predicts for stone fragmentation by shock wave lithotripsy. Urology 2008;72:765-9. 